\title{
Aluminium Binding Amount of Dietary Fiber Extracted from 14 Kinds of Food
}

\author{
Emiko TAKEYAMA ${ }^{1}$, Masako FuKUSHIMA ${ }^{1}$ and Akio TANIMURA ${ }^{2}$ \\ ${ }^{1}$ Faculty of Life Science, ${ }^{2}$ Science for Living System, Graduate School, Showa Women's University, 1-7, Taishido, Setagaya-ku, Tokyo 154-8533, \\ Japan
}

Received July 31, 2001; Accepted April 5, 2002

\begin{abstract}
We studied the impact of heating on the aluminium ion $\left(\mathrm{Al}\left(\mathrm{NO}_{3}\right)_{3}\right)$ binding amount of IDF (insoluble dietary fiber) and SDF (soluble dietary fiber) fractions extracted by the modified Prosky method from 14 kinds of food after different heat treatments. Al binding of unheated IDF was high in edible burdock, carrot, cabbage and hijiki. Heating marginally raised the $\mathrm{Al}$ binding amount of aloe and okra, but the other samples showed a tendency for the Al binding amount to fall when heated. Al binding of unheated SDF was extremely high in aloe, which has a high mucilage content, followed by okra and eggplant. Whereas non-mucilaginous foods had lower binding capacities when heated, the binding capacities of such viscous foods as aloe, okra, and moroheiya were increased by microwaving.
\end{abstract}

Keywords: dietary fiber, $\mathrm{Al}$ binding, heating

Dietary fiber (DF) is known to possess such physiological actions as normalization of the intestinal environment and inhibition of sugar absorption (Hanai et al., 1997; Anderson et al., 1995; Salmeron et al., 1997; Jenkins et al., 1995; Davidson \& McDonald, 1998). DF is also comprised of acidic polysaccharides that have a polar group, and acts to bind with, adsorb and promote to excretion a variety of metal ions by intermolecular force, chemical and physical factors that stem from its polysaccharide structure (Ou et al., 1999; Schrijver \& Conrad, 1992). DF is usually ingested from heated foods. At the same time, the polysaccharide structure of DF has been shown in experiments by the authors (Takeyama et al., 2002) to be affected both physically and chemically by heating.

SDF (soluble dietary fiber) and IDF (insoluble dietary fiber) fractions were extracted via modified Prosky method (Prosky et al., 1988) from 14 different heated samples, and the influence of heating on the metal binding ability that is a function of DF was determined.

Aluminium nitrate $\left(\mathrm{Al}\left(\mathrm{NO}_{3}\right)_{3}\right)$ was used as the metal ion. Aluminium (Al) is known to accumulate in the brain and may cause neurotoxic injury by long-term exposure (Sarin et al., 1997; Oshiro et al., 1998; Gonda \& Lehotzky, 1996; Bielarczyk et al., 1998; Gandolfi et al., 1998).

\section{Materials and Methods}

Materials We used 14 different samples in our study: aloe, okra, moroheiya, cabbage, celery, eggplant, bitter gourd, edible burdock, carrot, Japanese radish, hijiki, shiitake, nameko and common mushroom. Each sample was washed and wiped dry, whereupon the edible portion was either grated, using a plastic or ceramic grater, or minced with a ceramic knife. A portion of each sample was intermittently heated in a microwave oven for $13 \mathrm{~min}$, or autoclaved at $121^{\circ} \mathrm{C}$ for $30 \mathrm{~min}$. The processed samples were then freeze dried together with the unheated sam-

E-mail: takeyama@swu.ac.jp ples, then pulverized and put through a 32-mesh sieve for use in the study. All equipment was soaked overnight in $15 \%$ nitric acid solution, then washed with tap water or purified water before use.

Extraction of IDF and SDF by the modified Prosky method Two to 6 grams of the samples obtained mentioned above were subjected to extraction by the modified Prosky method (Prosky et al., 1988) as described in a previous report (Takeyama et al., 2002), followed by dialysis and freeze drying, to obtain IDF and SDF fractions.

Measurement of binding amount of Al with SDF To $2 \mathrm{ml}$ of solution containing $20 \mu \mathrm{g}$ of $\mathrm{Al}$ ion $\left(\mathrm{Al}\left(\mathrm{NO}_{3}\right)_{3}\right), 10 \mathrm{ml}$ of solution containing $10-20 \mathrm{mg}$ of SDF fraction and $3 \mathrm{ml}$ of water were added to a $50 \mathrm{ml}$ measuring flask (in pairs), and allowed to shake at room temperature for $1 \mathrm{~h}$. Twenty-five milliliters of $0.3 \%$ sodium mercaptoacetate solution was added to one measuring flask and $25 \mathrm{ml}$ of $0.04 \%$ EDTA solution was added to another. Five milliliters of $0.075 \%$ eriochrome cyanine R solution and $5 \mathrm{ml}$ of $4.15 \mathrm{M}$ ammonium acetate buffer ( $\mathrm{pH}$ 6.0) were then added to both flasks and the flasks filled with distilled water. These were then measured at $535 \mathrm{~nm}$ by absorption photometry using eriochrome cyanine R (Muki Oyo Hishoku Bunseki Hensyu Iinkai, 1973). The remaining quantity of $\mathrm{Al}$ ion was subtracted from $20 \mu \mathrm{g}$ to calculate the binding amount.

Measurement of binding amount of Al with IDF Fifteen to $30 \mathrm{mg}$ of IDF sample was measured into a conical beaker, to which $3 \mathrm{ml}$ of purified water was added; mixing with a glass stick followed, $5 \mathrm{ml}$ of $4 \mu \mathrm{g} / \mathrm{ml} \mathrm{Al}$ standard solution was added and the mixture was allowed to shake at room temperature for 1 h. Using an Advantec Toyo No. 5C filter paper, the mixture was filtered by suction into a $50 \mathrm{ml}$ measuring flask, whereupon the residue on the filter was washed thoroughly with $5 \mathrm{ml}$ of $0.1 \mathrm{M}$ $\mathrm{HCl}$ and water, then brought to a constant volume. The $\mathrm{Al}$ ion in the filtrate was analyzed with chrome azurol S (Muki Oyo Hishoku Bunseki Hensyu Iinkai, 1973). Ten milliliters of this solution, $0.6 \mathrm{ml}$ of $0.5 \mathrm{M} \mathrm{HCl}$ solution, $10 \mathrm{ml}$ of $0.02 \%$ Chromazurol S, $0.05 \%$ CTMAC (cetyl trimethyl ammonium chloride) 
solution and $5 \mathrm{ml}$ of $4 \mathrm{M}$ ammonium acetate buffer ( $\mathrm{pH} 6.3$ ) were added to measuring flask which was then filled to $50 \mathrm{ml}$ (pH 5.9). Al ion was analyzed at $620 \mathrm{~nm}$ using a blank sample, and the quantity of bound $\mathrm{Al}$ was calculated from the quantity of residual $\mathrm{Al}$ ion in the same manner as used in SDF.

\section{Results and Discussion}

The Al binding capacities of IDF are shown in Fig. 1. With IDF extracted from unheated samples, high levels of Al binding were seen for edible burdock, carrot, cabbage, and hijiki. Edible burdock in particular had a high rate of Al binding, approximately $2 \mathrm{mg}$ per gram of dried IDF fraction.

The DF amounts were shown in the previous report (Takeyama et al., 2002). These amounts of unheated IDF extracted from edible burdock, carrot, cabbage and hijiki were also higher than their heated samples.

A report by Yoshida and Saito (1985) describes an especially high hemicellulose content of raw carrot and raw eggplant, and high hemicellulose and lignin contents of raw edible burdock. In fact, xylan, which included uronic acid or protein, was shown to have Al binding ability (Fukushima \& Tanimura, 1995). In short, the Al binding amount of xylan is believed to be greatly influenced by its uronic acid content. It is conceivable that the ratio of hemicellulose in DF and its structure might be closely related to Al binding.

The absorption amount of Al by unheated hijiki DF was $1070 \mu \mathrm{g} / \mathrm{g}$, and autoclaved and microwaved hijiki DF were absorbed each $781 \mu \mathrm{g} / \mathrm{g}$ and $807 \mu \mathrm{g} / \mathrm{g}$. Hijiki is a kind of brown alga; the dried polysaccharides of brown alga are $10-47 \%$ of alginic acid, whose primary constituents are mannuronic acid and gluronic acid (Maeda \& Nishizawa, 1974). It can be surmised that the $-\mathrm{COOH}$ of alginic acid has high activity and so had an impact on Al binding. It should be noted that, because alginic acid is readily depolymerized when heated in an acidic solution, it is possible that the autoclaving caused it to transfer into the water soluble fraction.

With heating, Al binding amount of the IDF fraction rose slightly in fractions extracted from autoclaved and microwaved aloe and okra, while in other samples, the Al binding amount of IDF fractions decreased after heat processing. In particular, the Al binding capacities of IDF fractions extracted from autoclaved and microwaved edible burdock and carrot showed marked decreases.

The amounts of unheated and heated DF (IDF and SDF) for edible burdock and carrot were shown in a previous report (Takeyama et al., 2002); the particularly high hemicellulose content is very likely to have become soluble with heating and spilled over into the SDF fraction (about $10-30 \%$ of IDF), and this tendency was also true for soybean (Takeyama et al., 1996). With microwaved okra, microwaved common mushroom and microwaved bitter gourd, the IDF fractions (35.1, 27.6 and $32.1 \%$ ) increased over their non-heated counterparts $(30.3,24.8$ and $29.8 \%$ ) (Takeyama et al., 2002), and a tendency was seen for a greater increase in $\mathrm{Al}$ binding amount for those foods that showed substantial increases. The increase of IDF is believed to be attributable to a part of the soluble portion having become insoluble.

Meanwhile, SDF fractions contain large quantities of water soluble hemicellulose, pectin, vegetable gum, and mucopolysaccharides. As shown in Fig. 2, the Al binding capacities of the SDF fractions extracted from the 14 different foods showed high values when unheated for aloe, okra and eggplant. Aloe in particular had extremely high values. As the SDF of aloe contains an especially high amount of galactan and mucopolysaccharides

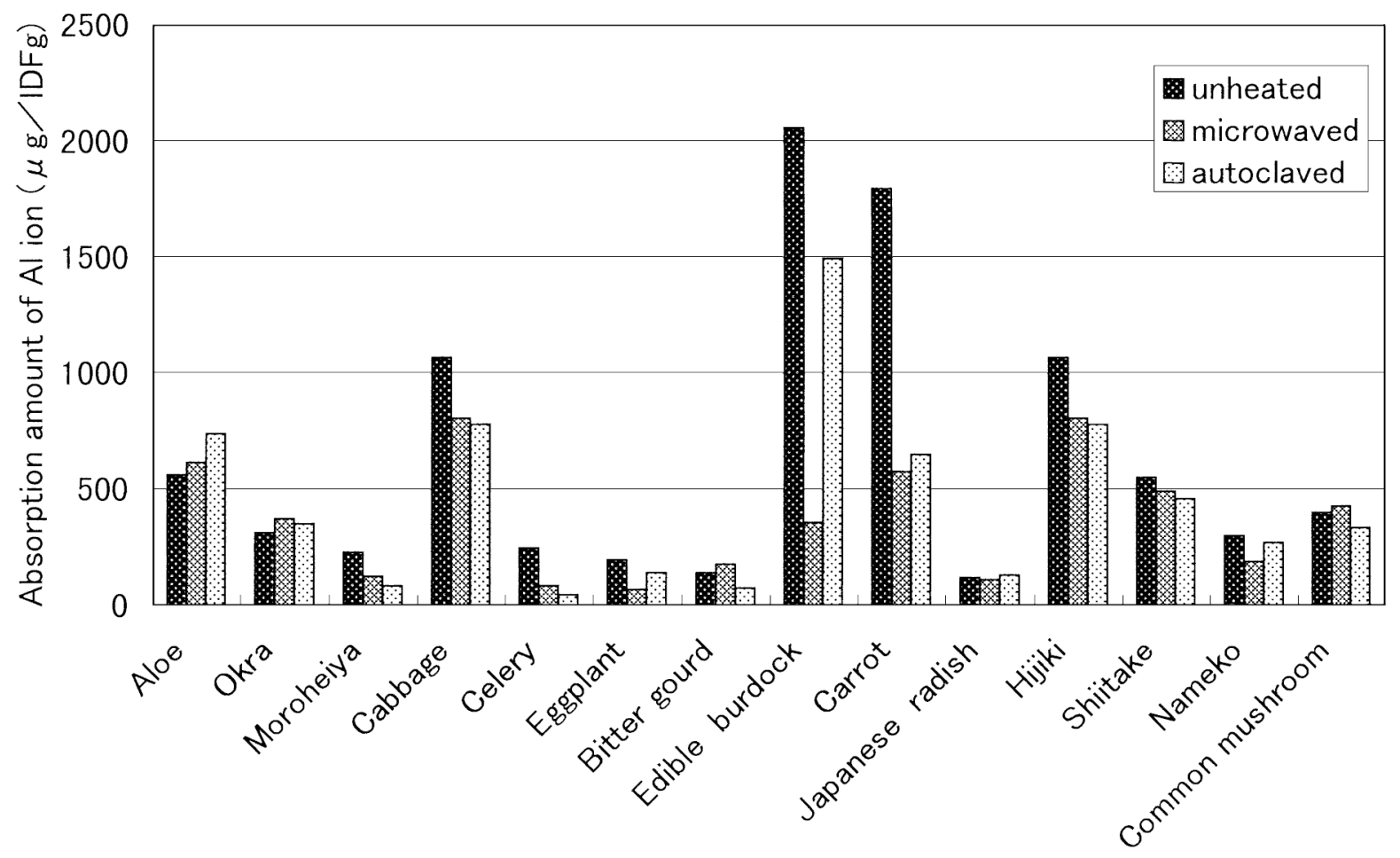

Fig. 1. Absorption amount of AI ion by IDF. 


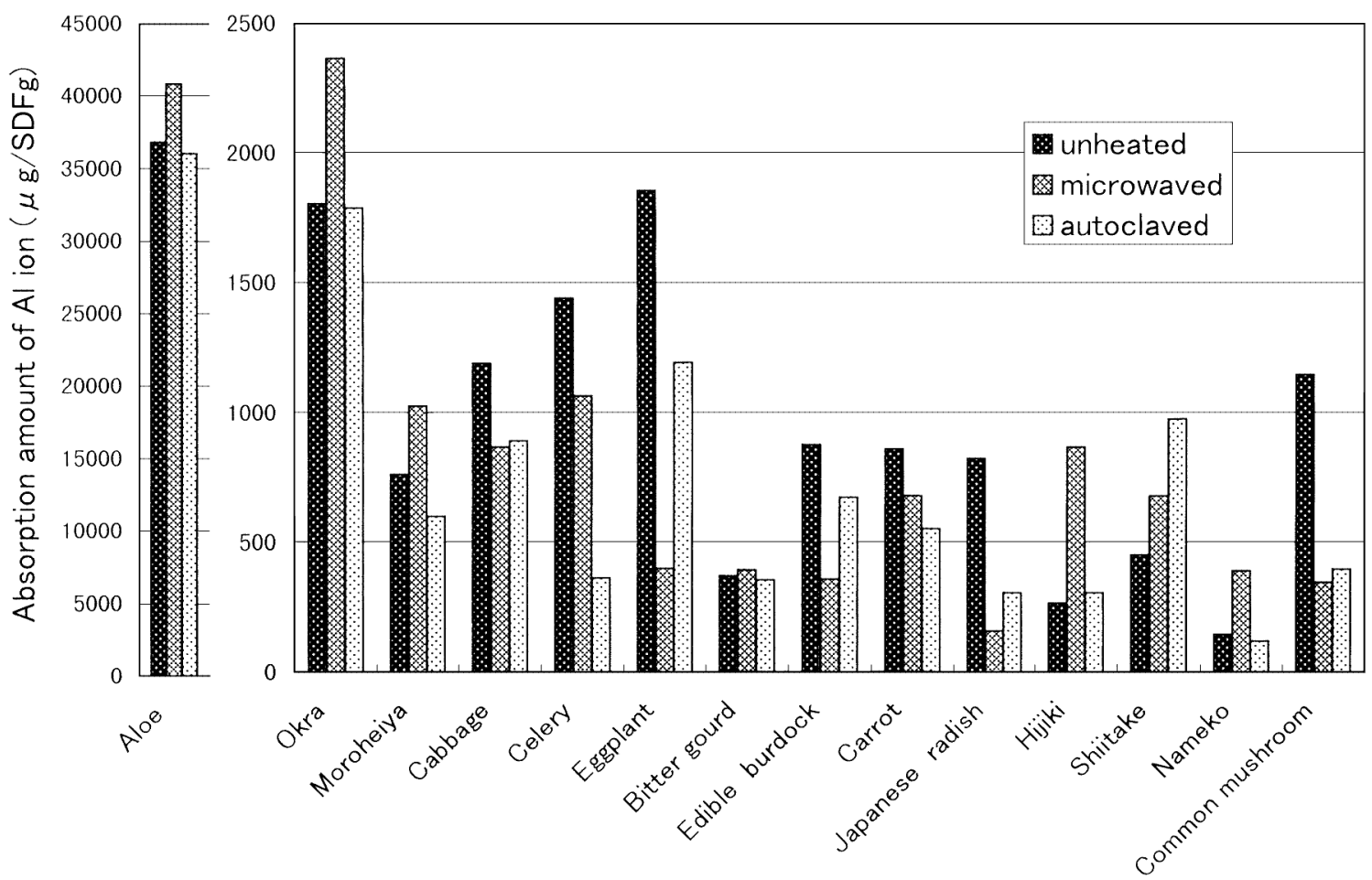

Fig. 2. Absorption amount of AI ion by SDF.

(Dweck, 1999; Yasuda et al., 1999), it is conceivable that the galacturonic acid attached to the galactan and the mucilage primarily consisting of mucopolysaccharides formed chemical and / or physical bonds with $\mathrm{Al}$.

The mucilage of okra is composed of such substances as pectin, galactan, and araban (Egami et al., 1969; Miyazaki,1990) . It is conceivable that the $\mathrm{Al}$ binding amount was enhanced due to the particularly high content of acidic sugars, which have cationic exchange properties, in pectin and hemicellulose. However, moroheiya, which also had a high ratio of acidic polysaccharide (ca 65\% of DF) (Otani et al., 1995), had a lower Al binding ability compared to okra. These differences are believed to responsible for the sugar composition of DF, which is mainly comprised of glucuronic acid in moroheiya (ca 43\%) but galacturonic acid in okra (ca 33\%).

The Al binding amount for SDF fractions extracted from heat processed samples decreased in over half the samples, but it increased in microwaved aloe, okra, moroheiya, nameko, and hijiki, as well as in autoclaved and microwaved shiitake. While autoclaving had the effect of decreasing Al binding amount for almost all other samples, the Al binding quantity of shiitake went up to approximately twice its unheated values. Considering that shiitake contains a large amount of free amino acids such as glutamic acid, which may react with saccharides to form melanoidin (Kurasawa et al., 1982, 1991), the increase of Al binding may be partially caused by the formation of melanoidin, which is reported to have metal binding activity (Horikoshi \& Gomyo, 1976).

The IDF of hijiki has a high alginic acid content, which depolymerizes with autoclaving (Tsuji \& Mori, 1998). However, microwaving does not cause as much depolymerization as autoclaving, and it is highly probable that the alginic acid remained within the SDF fraction. It is conceivable that for this reason the Al binding amount became particularly high with microwaving. Nevertheless, further examination is required on the details.

Based on the above experiments, we found that $\mathrm{Al}$ binding amount with DF changed remarkably by heating. But the effects of heating could not be simplified, and the variation in ranges differed in each food. Especially, mucilaginous and non- mucilaginous foods showed quite opposite results. The DF was affected by heating, and we found the same true in $\mathrm{Al}$ binding as shown in many other reports.

A portion of this study was funded by a 2000-2001 Grant-in-Aid for Scientific Research from Japan Society for the Promotion of Science. The authors wish to express their gratitude.

\section{References}

Anderson, J.W., O’Neal, D.S., Riddell-Mason, S., Floore, T.L., Dillon, D.W. and Oeltgen, P.R. (1995). Postprandial serum glucose, insulin, and lipoprotein responses to high- and low-fiber diets. Metabolism, 44, 848-854.

Bielarczyk, H., Tomaszewicz, M. and Szutowicz, A. (1998). Effect of aluminum on acetyl-CoA and acetylcholine metabolism in nerve terminals. J. Neurochem., 70, 1175-1181.

Davidson, M.H. and McDonald, A. (1998). Fiber: Forms and functions. Nutr. Res., 18, 617-624.

Dweck, A.C. (1999). The aloe (Aloe barbadensis Miller), SÖFW-J., 125, 20-23.

Egami, F., Suzuki, T., Matsumura, T. and Yamashina, I. (1969). "Tatorui Seikagaku: kagaku hen” Kyoritsu Shuppan, Tokyo, pp. 293 (in Japanese).

Fukushima, M. and Tanimura, A. (1995). Binding property of aluminium ion to dietary fiber, polyphenol compounds and organic acids. Nippon Shokuhin Kagaku Kogakukaishi, 42, 425-429 (in Japanese).

Gandolfi, L., Stella, P.M., Zambenedetti, P. and Zatta, P. (1998). Aluminum alters intracellular calcium homeostasis in vitro. Biochim. Biophys. Acta, 1406, 315-320. 
Gonda, Z and Lehotzky, K. (1996). Effect of prenatal aluminium lactate exposure on conditioned taste aversion and passive avoidance task in the rat. J. Appl. Toxicol., 16, 529-532.

Hanai, H., Ikuma, M., Sato, Y., Hosoda, Y., Matsushita, I., Nogaki, A., Yamada, M. and Kaneko, E. (1997). Long-term effects of water-soluble corn bran hemicellulose on glucose tolerance in obese and nonobese patients: improved insulin sensitivity and glucose metabolism in obese subjects. Biosci. Biotechnol. Biochem., 61, 1358-1361.

Horikoshi, M. and Gomyo, T. (1976). Precipitation of protein in the presence of melanoidin. Agric. Biol. Chem., 40, 1531-1537.

Jenkins, D.J., Jenkins, A.L., Woleveer, T.M., Vuksan, V., Rao, A.V., Thompson, L.U. and Josse, R.G. (1995). Effect of reduced rate of carbohydrate and lipid metabolism. Eur. J. Clin. Nutr., 49, S68-S73.

Kurasawa, S., Sugahara, T. and Hayashi, J. (1982). Proximate and dietary fibre analysis of mushrooms. Nippon Shokuhin Kogyo Gakkaishi, 29, 400-406 (in Japanese).

Kurasawa, S., Sugahara, T. and Hayashi, J. (1991). Determination of dietary fiber in chitin-containing mushrooms by the enzymaticgravimetric method. Nippon Eiyo Shokuryo Gakkaishi, 44, 293-303 (in Japanese).

Maeda, M. and Nishizawa, K. (1974). Kaiso Tatourui. In "Sogo Tatourui Kagaku (ge)" ed. by A. Harada and A. Misaki. Kodansha scientific, Tokyo, pp. 311-312. (in Japanese).

Miyazaki, T. (1990). "Tato no Kozo to Seirikassei" Asakura Shoten, Tokyo, p.106 (in Japanese).

Muki Oyo Hishoku Bunseki Henshu Iinkai (1973). "Muki oyo hisyoku bunseki” Kyoritsu Shuppan, Tokyo, pp. 46-51. (in Japanese).

Oshiro, S., Kawahara, M., Mika, S., Muramoto, K., Kobayashi, K., Ishige, R., Nozawa, K., Hori, M., Yung, C., Kitajima, S. and Kuroda, Y. (1998). Aluminum taken up by transferrin-independent iron uptake affects the iron metabolism in rat cortical cells. J. Biochem., 123, 42-46.

Otani, K., Okai, K., Yamashita, U., Yuasa, I. and Misaki, A. (1995). Characterization of an acidic polysaccharide isolated from the leaves of corchorus olitorius (Moroheiya). Biosci. Biotechnol. Bio- chem., 59, 378-381.

Ou, S., Gao, K. and Li, Y. (1999). An in vitro study of wheat bran binding capacity for $\mathrm{Hg}, \mathrm{Cd}$, and $\mathrm{Pb}$. J. Agric. Food Chem., 47, 4714-4717.

Prosky, L., Asp, N.G., Schweizer, T.F., Devries, J.W. and Furda, I. (1988). Determination of insoluble, soluble, and total dietary fiber in foods and food products: Interlaboratory study. J. Assoc. Off. Anal. Chem., 71, 1017-1023.

Salmeron, J., Manson, J.E., Stampfer, M.J., Colditz, G.A., Wing, A.L. and Willett, W.C. (1997). Dietary fiber, glycemic load, and risk of non-insulin-dependent diabetes mellitus in women. J. Am. Med. Assoc., 277, 472-477.

Sarin, S., Julka, D. and Gill, K.D. (1997). Regional alterations in calcium homeostasis in the primate brain following chronic aluminium exposure. Mol. Cell. Biochem., 168, 95-100.

Schrijver, R.D. and Conrad, S. (1992). Availability of calcium, magnesium, phosphorus, iron, and zinc in rat fed oat bran containing diet. J. Agric. Food Chem., 40, 1166-1171.

Takeyama, E., Yokokawa, N. and Tanimura, A. (1996). Changes in polysaccharide components and metal adsorption ability of soybean dietary fiber on heating. Nippon Shokuhin Kagaku Kogaku Kaishi, 43, 231-237 (in Japanese).

Takeyama, E., Fukushima, M. and Tanimura, A. (2002). Effect of heattreatment on the content and polysaccharide composition of dietary fiber. Food Sci. Technol. Res., 8, 125-130.

Tsuji, K. and Mori, B. (1998). "Shokumotsuseni no kagaku" Asakura Shoten, p. 23, 61 (in Japanese).

Yasuda, K., Dohgasaki, C. and Nishijima, M. (1999). Mitogenic activity of Aloe araborescens Miller, Aloe barbadensis Miller and Aloe africana Miller. Nippon Shokuhin Hozokagaku Kaishi, 25, 201-207 (in Japanese).

Yoshida, S. and Saito, Y. (1985). Effect of cooking on water insoluble dietary fiber in vegetables. Kaseigaku Zasshi, 36, 721-725 (in Japanese). 